\title{
COOPERAÇÃO E EMPATIA: UMA ARTICULAÇÃO EM FAVOR DOS FUNDAMENTOS NATURAIS PARA A MORALIDADE
}

\section{COOPERATION AND EMPATHY: AN ARTICULATION IN FAVOR OF THE NATURAL FOUNDATIONS FOR MORALITY}

\author{
Rafael Francisco Hiller ${ }^{1}$ \\ Heloisa Allgayer ${ }^{2}$
}

Recebido: 04/2019

Aprovado: 10/2019

\begin{abstract}
Resumo: O objetivo deste artigo é trazer subsídios teóricos e empíricos que possam fundamentar uma abordagem naturalista do fenômeno moral. A moralidade, neste artigo, será entendida enquanto um fenômeno necessário para a manutenção da vida em grupo dos mamíferos sociais de vida complexa. Tal hipótese será defendida ao longo deste trabalho, a partir da defesa de uma relação existente entre empatia e cooperação dentro do grupo de grandes primatas, mais especificamente nas comunidades de Chimpanzés (Pan troglotydes versus). Esta pesquisa está ancorada pelas descobertas realizadas por Hume, principalmente, nas discussões em torno da sua proposta de tratar as questões pertencentes ao campo da filosofia moral a partir do emprego de métodos experimentais, bem como por novos avanços nas ciências biológicas e cognitivas que permitem buscar novas resoluções para as indagações presentes há séculos no campo especulativo da filosofia moral. As pesquisas etológicas com primatas fornecem subsídios indispensáveis para a sustentação da hipótese de que algumas emoções aparecem como resposta a certos fatos socialmente considerados de grande valia. Desta forma, intento demonstrar que os elementos indispensáveis para o surgimento de um determinado fenômeno moral estão contidos na estrutura biológica de mamíferos sociais de vida complexa. Certamente, os dados empíricos e teóricos trazidos por esta pesquisa, contribuem de forma significativa para a sustentação do argumento a favor de uma teoria que procura entender a moralidade através de bases evolucionistas.
\end{abstract}

Palavras-Chaves: Empatia; Cooperação; Etologia; Hume; Evolução

\begin{abstract}
The objective of this paper is to bring theoretical and empirical subsidies that can base a naturalistic approach to the moral phenomenon. Morality, in this article, will be understood as a necessary phenomenon for the maintenance of group life of social mammals of complex life. This hypothesis will be defended throughout this work, from the defense of a relationship between empathy and cooperation within the group of great primates, more specifically in the communities of Chimpanzés (Pan troglotydes versus). This research is anchored by the discoveries made by Hume, mainly in the discussions around his proposal to deal with the questions pertaining to the field of moral philosophy from the use of experimental methods, as well as by new advances in the biological and cognitive sciences that allow to search new resolutions to the questions that have been present for centuries in the speculative field of moral philosophy. The ethnological researches with primates provide indispensable subsidies for the support of the hypothesis that some emotions
\end{abstract}

\footnotetext{
${ }^{1}$ Bacharel em filosofia, mestre em Comunicação pela Universidade do Vale do Rio dos Sinos e Mestre em Filosofia pela Universidade de Caxias do Sul. rafaelhiller@yahoo.com.br

${ }^{2}$ Mestra em Filosofia pela Universidade do Vale do Rio dos Sinos e bolsista de Doutorado em Biologia Molecular (CAPES) da Universidade do Vale do Rio dos Sinos. heloisaallgayer@gmail.com
} 
appear in response to certain socially considered facts of great value. In this way, I try to demonstrate that the indispensable elements for the emergence of a certain moral phenomenon are contained in the biological structure of social mammals of complex life. Certainly, the empirical and theoretical data brought by this research contribute significantly to support the argument for a theory that seeks to understand morality through evolutionary foundations.

Keywords: Empathy; Cooperation; Ethology; Hum and; Evolution

\section{Um panorama geral sobre as possibilidades de realização de pesquisa de filosofia experimental com grandes primatas}

O objetivo deste artigo é argumentar em favor da relação entre a teoria moral de Hume e as ciências naturais. Vamos elencar os principais pontos de conectividade entre as duas temáticas, a fim de, justificar a viabilidade dessa pesquisa e afirmar a importância da compreensão das relações sociais no que concernem os mamíferos sociais de vida complexa.

Para Hume a posição de que os juízos morais possuem como fundamento os sentimentos. Nesse sentido, o estudo de chimpanzés (Pan troglotydes versus), a saber, mamíferos que vivem em sociedades complexas, auxiliam na validação da hipótese humeana. Sendo assim, para Crailsheim:

Os animais sociais de vida complexa são mamíferos altamente sociais, incluindo os humanos, viver em grupo exige a capacidade de estabelecer e manter relações sociais, de buscar e tolerar a companhia de indivíduos da mesma espécie, e lidar com imprevisíveis e, possivelmente estressantes eventos sociais. ${ }^{3}$ (CRAILSHEIM, 2011, p.1)

Já no que diz respeito a argumentação Humeana Brito (2001), afirma que:

Se por ventura não tivéssemos por natureza a inclinação para gostar do que é útil, não haveria moral, ou pelo menos ela seria algo muito diferente, se, por exemplo, tivéssemos a inclinação para gostar do que não nos é útil. O que parece francamente absurdo, pois, neste caso, a moral nos teria levado a extinção. (BRITO, 2001, p. 23)

É a partir da citação acima, através da relação entre os conceitos de utilidade e moralidade, que podemos começar a conectar o pensamento de Hume com as bases da moderna teoria evolucionista. Pois, segundo Darwin (1872a, p.75), "a seleção natural atua apenas pela

3 In highly social mammals, including humans, group living requires the capability to establish and maintain social relationships, to seek and tolerate the company of conspecifics, and to cope with unpredictable and possibly stressful social events. 
conservação e acumulação de pequenas modificações herdadas, cada característica rentável para o ser, é preservada [...]"4 $\mathrm{O}$ instinto social, para surgir, depende do acúmulo de características aleatórias. Tal instinto é o que todos os animais sociais compartilham, pois é mediante ele que ocorrem os agrupamentos de tais grupos. Quando tratamos de animais sociais de vida complexa, algo ser útil não envolve somente aquilo que é útil para apenas um indivíduo, mas sim para toda a comunidade a qual ele pertence. Entretanto, somente a capacidade de sentimentos de aprovação ou reprovação não é o suficiente para classificarmos um grupo de animais como morais.

A empatia ${ }^{5}$ entre os indivíduos é indispensável, pois é esta capacidade adquirida evolutivamente que permite que os animais sociais de vida complexa não apenas sejam capazes de perceberem as emoções alheias, mas também possam senti-las como se fossem suas. Para Hume:

É provável que a sentença final [...] que torna a moralidade um princípio ativo e faz da virtude nossa felicidade e do vício nossa miséria - é provável, eu dizia, que essa sentença final se apoie em algum sentido interno ou sensação que a natureza tornou universal na espécie inteira (HUME, 2004, p.229).

O senso de utilidade como algo bom, pode ter surgido a partir de uma predisposição já existente nos indivíduos. Para tal característica se fixar na espécie é necessário que ela fosse vantajosa ou neutra. Além do senso de utilidade, é indispensável para os mamíferos sociais que o julgamento de algo bom ou ruim esteja relacionado com os laços estabelecidos com os membros de sua população. Pois esse sentimento foi, e continua sendo, crucial para o desenvolvimento e a perpetuação dos mamíferos sociais, principalmente, aqueles com organizações sociais complexas.

Para que os animais sociais possam se organizar em sociedade é preciso haver intercomunicação entre os indivíduos. Segundo Darwin (1872b, p.60), com tais grupos, “o poder de intercomunicação entre os membros da mesma comunidade, - e com outras espécies, entre os sexos opostos, assim como entre os jovens e os velhos, - é da mais alta importância."

\footnotetext{
${ }^{4}$ Natural selection acts only by the preservation and accumulation of small-inherited modifications, each profitable to the preserved being $(\ldots)$

${ }^{5} \mathrm{Na}$ psicologia e nas neurociências contemporâneas a empatia é uma espécie de mecanismo que pode ser dividido em dois tipos: o cognitivo - relacionada com a capacidade de compreender a perspectiva psicológica das outras pessoas; e o afetivo - relacionado com a habilidade de experimentar reações emocionais por meio da observação da experiência alheia. Faz-se necessário salientar que, durante este trabalho, sempre que utilizarmos o termo simpatia, presente na maioria dos escritos antes do século XX, está, na verdade, referindo-se ao conceito de empatia.
} 
${ }^{6}$ Assim, segundo Darwin:

No momento da ação, o homem, sem dúvida, está apto a seguir o impulso mais forte e, embora isso possa ocasionalmente levá-lo às mais nobres ações, ele irá mais comumente satisfazer os seus próprios desejos em detrimento de outros homens. Mas depois de sua gratificação, quando as impressões passadas e mais fracas são julgadas pelo instinto social, e pelo seu profundo respeito a boa opinião de seus companheiros, a retribuição certamente virá. Ele, então, sente o remorso, o arrependimento, a vergonha, sendo o sentimento último, no entanto, referente quase exclusivamente ao julgamento dos outros. (DARWIN, 1981, p.64). ${ }^{7}$

O homem se sente bem ao ser elogiado por uma boa conduta em relação a outro de sua comunidade. Tal sentimento vem pelas complexas relações sociais que permitiram a perpetuação e o sucesso evolutivo de sua espécie. As complexas relações sociais ocorrem também em outras espécies de mamíferos, o sentimento de reprovação do grupo, o sentimento de tristeza diante da perda de um membro, não é uma exclusividade do Homo sapiens.

Pertencer a um grupo pode ser definido como estar apto não só para seguir uma regra, mas também para reagir quando há uma quebra na norma, seja ela cometida por si ou por outro membro. (TUGENDHAT,1997). A manutenção de um grupo social envolve mais que uma simples relação de trocas de benefícios entre os indivíduos, levando à uma complexa teia onde todos podem afetar todos. É essa complexa estrutura que permite as mais diversas interações sociais.

A complexa teia de inter-relações entre os indivíduos faz com que haja uma troca de sentimentos. Essa troca faz com que as afeições deixem de ser algo particular e subjetivo e passem a servir como um fator regulador das atividades sociais. A empatia, neste caso, atua enquanto uma qualidade natural que permite que os seres de vida social complexa compartilhem experiências sentimentais que serviram de manutenção da vida em grupo de tais comunidades. Desta forma, para Darwin:

[...] por maior peso que possamos atribuir à opinião pública, a nossa relação de

\footnotetext{
6 "With social animals, the power of intercommunication between the members of the same community,--and with other species, between the opposite sexes, as well as between the young and the old, -- is of the highest importance to them."

7 At the moment of action, man will no doubt be apt to follow the stronger impulse; and though this may occasionally prompt him to the noblest deeds, it will more commonly lead him to gratify his own desires at the expense of other men. But after their gratification when past and weaker impressions are judged by the ever-enduring social instinct, and by his deep regard for the good opinion of his fellows, retribution will surely come. He will then feel remorse, repentance, regret, or shame; this latter feeling, however, relates almost exclusively to the judgment of others.
} 
aprovação e desaprovação dos nossos companheiros, depende da simpatia, que [...] constitui uma parte essencial do instinto social e é de fato sua pedra fundamental. (DARWIN, 1981, p.62-3) ${ }^{8}$

Para Hume (2004, p.351) a empatia consiste em “[...] nossa propensão a simpatizar com os outros e a receber por comunicação suas inclinações e sentimentos, por mais diferentes ou até contrários aos nossos". Sendo assim a empatia é capacidade básica para que possamos ter certos sentimentos morais. Em uma comunidade os indivíduos comunicam suas sensações e inclinações, sendo regulada pelos próprios membros, essa é a qualidade natural da empatia. É através deste mecanismo que ocorre a comunicação de um ser para outro, assim como as respostas a tal comunicação. Através desta qualidade natural que se constrói a complexa teia social, que torna as sociedades de mamíferos sociais mais complexas do que a dos invertebrados sociais onde cada indivíduo apenas representa um papel bem definido e onde todos os indivíduos são irmãos.

O método utilizado para as investigações de distinções morais e compreensão da moral nesse artigo terá um aporte principalmente nos escritos de Hume, bem como nos escritos dos seus interlocutores e em revisão de literatura empírica de artigos da área das ciências naturais. Para a elaboração desse trabalho algumas áreas serão contempladas devido a sua relevância empírica, sendo elas as neurociências, a biologia evolutiva, a ecologia, a etologia e a psicologia cognitiva. Para Brito (2001, p.11), "Se há algo para investigar a propósito da moral, então, sob a perspectiva do empirismo, isto deveria estar no mundo e pode ser como tudo o mais, objeto de experiência; isto é, deveria ser empírico."

A investigação dos processos morais será realizada através da observação das inclinações dos animais que compõe os grupos sociais complexos por meio da revisão de uma dissertação da área de etologia, bem como de artigo de evolução biológica entre 2008 e 2018 . A descrição comportamental dos indivíduos que compões tais sociedades é o que permitirá caracterizar o fundamento das distinções morais. Há evidências que favorecem a hipótese de que juízos morais ordinários são fundamentalmente emocionais. Note-se que indivíduos expostos a situações consideradas como incorretas dentro da dinâmica social do grupo tendem a ter uma reação de desaprovação. Através de diversos estudos na área da psicologia cognitiva tal afirmação vem sendo confirmada, ver, por exemplo, os estudos realizados por Tracy e Matsumoto em 2008.

\footnotetext{
${ }^{8}[\ldots]$ however great weight we may attribute to public opinion, our regard for the approbation and disapprobation of our fellows depends on sympathy, which [...] forms an essential part of the social instinct, and is indeed its foundation-stone.
} 
Os primeiros sinais comportamentais como companheirismo, alegria, raiva devem surgir durante as fases que serão observadas. Nesse sentido, é possível determinar os primeiros sentimentos que surgem para a construção moral em um grupo social. Já na infância tais animais poderão ser punidos se estiverem sendo egoístas, como serão castigados por outras atitudes consideradas socialmente incorretas. É importante ressaltar que tal punição gerará diferentes reações nos indivíduos. Em grupos sociais os egoístas, serão punidos, pois exploram aqueles animais que cooperam para o funcionamento e a manutenção da sociedade. $\mathrm{O}$ altruísmo é recompensado pela aprovação social do grupo.

A afirmação humeana de que o que é útil é bom se encaixa diretamente nesse aspecto social dos chimpanzés, onde o egoísta (sem utilidade) é punido pela sociedade e o cooperador que possui inclinações altruístas (útil) é recompensado. Mas as relações entre os indivíduos não são estabelecidas apenas pela utilidade do mesmo, a empatia, para tal estabelecimento, é fundamental. Através das relações sociais, e, consequentemente da empatia é possível compreender a inteligência de um grande primata. Segundo De Wall:

O único modo de obter uma ideia adequada da inteligência de um grande primata na o humano é conceber experimentos que o absorvam intelectualmente e emocionalmente. [...]. Eles se interessam é por situações sociais envolvendo indivíduos que lhes são próximos. Salvar um infante de um ataque, passar a perna em um rival, evitar conflito com um líder, esgueirar-se de ser visto com um parceiro sexual, esses são os tipos de problemas que os primatas gostam de resolver. (DEWALL, 2007, p.225)

As neurociências em seus experimentos realizam um escaneamento cerebral, demonstrando, desta forma, quais partes tornam-se ativas mediante a exposição de atitudes moralmente incorretas, que levam a uma reação de desaprovação. Porém, tal método não explica qual o papel dos sentimentos nas reações dos seres vivos quanto aos juízos morais.

Para uma compreensão do desenvolvimento moral, a etologia e a biologia evolutiva possuem um papel importante. O modelo PAM (Perception-Action Model, conforme desenvolvido por Preston e DeWall (2002), auxilia na explicação dos comportamentos dos animais. Através da observação do comportamento dos animais, bem como estudos evolutivos sobre o surgimento e fixação dos comportamentos, pode-se compreender as variações comportamentais que ocorrem mesmo em populações de uma mesma espécie, caso essas sejam afastadas. Para ser realizado um estudo com animais sociais, não basta apenas uma análise controlada de comportamento, mas também é necessária uma análise comportamental em meio natural de tal espécie. 
Os animais sociais de vida social complexa têm como base comum a empatia, estando entre eles o chimpanzé (Pan troglotydes versus). Tal espécie está próxima evolutivamente do Homo sapiens, como pode ser observado no cladograma abaixo:

Figura1- Cladograma representado o ancestral comum do Homo sapiens e do Pan troglotydes, a 6 milhões de anos.

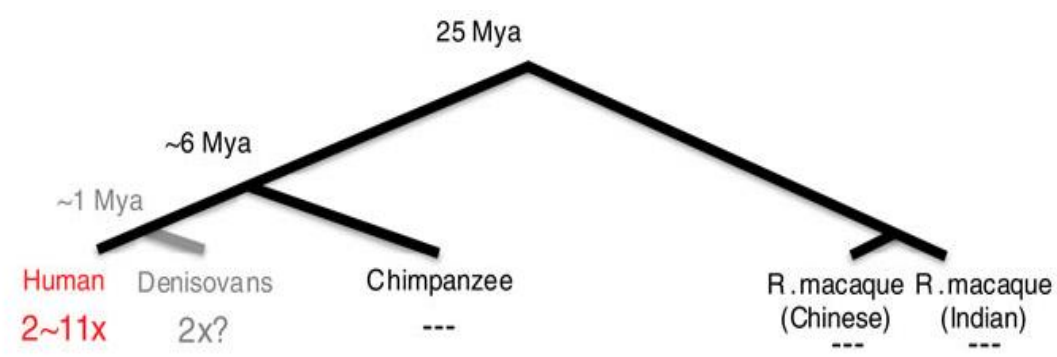

Fonte: HU, H. Y. et al. (2012)

Segundo Crailsheim (2011), os chimpanzés selvagens, dentre os primatas, são os animais que possuem a organização social mais complexa. Partindo do pressuposto de que a base da vida social é a cooperação mediada pela empatia e, devido à proximidade evolutiva de tal espécie com a humana, a revisão bibliográfica será feita por meio de artigos de etologia que realizaram um amplo e exaustivo estudo sobre o comportamento dos chimpanzés (Pan troglotydes versus).

Além disso, partimos do pressuposto de que as replicações de expressões são muito importantes nas interações sociais podendo servir similarmente como funções adaptativas em humanos e chimpanzés, isto é, promovem afiliação e coordenação social, adicionando o aprendizado de novos comportamentos (Bard, 2007; Bourgeois e Hess, 2008; Byrne, 2003; Hatfield, Cacioppo, e Rapson, 1994). Segundo Estrada (1991) atualmente a teoria da evolução considera o comportamento como um elemento central no processo evolutivo dos organismos, sendo um dos fatores nos quais a seleção natural opera.

\section{Etologia em primatas da subespécie Pan Troglodytes Verus: análise de um caso empírico}

Os mais diversos estudos no campo da etologia e das ciências antropológicas possuem 
a virtude de terem conseguido explicar à base biológica de alguns comportamentos humanos. Através de estudos rigorosos que almejavam descobrir tanto a motivação como o comportamento de outras espécies de animais. Segundo Carvalho (2008), os estudos a respeito do comportamento social de primatas não humanos são de grande valia para o entendimento da ontogenia comportamental da nossa espécie, ou seja, são encarados como um modelo de estágios evolutivos pelos quais, obrigatoriamente, o comportamento humano tenha passado.

As mais diversas conclusões à níveis comportamentais têm sido descobertas na nossa espécie, sendo assentadas, obviamente, tanto pela proximidade morfológica como genética, análoga em ambas as espécies. Segundo Carvalho (2008, pg. 9), “Outras evidências podem ser também salientadas: o número de indivíduos que constituem uma comunidade de caçadores/coletores é cerca de 150, um número não muito diferente da comunidade maior de chimpanzés". Mais ainda, segundo Carvalho (2008), a grande parte das sociedades humanas é definida pela dispersão das fêmeas e uma filantropia masculina. As comunidades de chimpanzés também apresentam indícios semelhantes. Segundo De Wall (1989), as diferenças entre nós e os chimpanzés se dão mais a nível quantitativo do que qualitativo.

As pesquisas realizadas a nível de padrões de comportamento e de organização social de chimpanzés, tem sido de grande valia para esclarecer como foi a vida hominídea na África desde os primórdios. Segundo Carvalho (2008), estas pesquisas buscam colocar a prova as teorias do comportamento social, e quando comparados com trabalhos realizados com os humanos auxiliam na classificação de características filogeneticamente conservadas. $O$ fundamento da análise parte de o fato dos seres humanos partilharem um mesmo ancestral comum recente com as quatro espécies de grandes antropoides (chimpanzés, bonobos, gorilas e orangotangos). (CARVALHO,2008).

Tem se verificado que a grande maioria deles possuem uma extensa flexibilidade e capacidade inventiva comportamental, pois se adaptam de forma perfeita a novas circunstâncias, criando os meios necessários para adquirem os benefícios sócias almejados. (CASANOVA, CEBALLOS, LEE, 2008).

Segundo Dunbar (1988), A formação de grupos permite uma maior eficácia na proteção contra predadores, defesas de recursos, procura de alimentos e etc... Internamente, nestes grupos, existem os mais variados tipos de indivíduos que tendem a atuar de acordo como o grau social que ocupam, havendo, desta forma, um custo específico para que a vida em grupo se consolide. Segundo Carvalho (2008), tais custo podem ser "pagos" se o mecanismo da cooperação entrar em vigor. 


\section{Estágio atual de pesquisas realizadas com chimpanzés.}

Os primeiros estudos etológicos realizados com chimpanzés foram promovidos por Jane Goodall nas margens do lago Tanganika (em Golpe). Atualmente são realizados estudos em quase todas as regiões aonde existe a ocorrência de tais primatas. Os chimpanzés vivem em habitats que se caracterizam basicamente por florestas tropicais e savanas, como uma distribuição que ocorre desde a Guiné-Bissau à Guiné Conacry, passando pela Costa do Marfim, Angola, Nigéria, Uganda, Ruanda e Tanzânia. (CASANOVA, 2006). Os chimpanzés possuem uma base alimentar basicamente composta de frutos, tubérculos e insetos. (CASANOVA, 2006). Produzem artefatos por meio de materiais disponíveis na natureza. Os chimpanzés, de forma geral, caçam cooperativamente outros primatas (Colobus e os Babuínos). A caça, geralmente, é observada nos machos, na medida em que o uso de ferramentas e de forma maioritária observado nas fêmeas. As fêmeas atuam de maneira muito sagaz no que concerne a coleta de alimentos de forma extrativa, extração esta que requer o uso de instrumentos. Os machos, ao contrário, se empenham muito mais nas caçadas realizadas em busca de recursos, embora, de maneira esporádica, as fêmeas que por algum motivo não tiveram crias se torna eximias caçadoras. Podemos afirmar que, a cooperação entre machos, é bem mais intensa e facilmente observável devido ao seu envolvimento na tarefa de defesa de território.

\section{Comportamento Social em Chimpanzés: análise de um caso empírico}

$\mathrm{O}$ caso que trataremos a seguir se refere a uma dissertação de mestrado defendida $\mathrm{Na}$ Faculdade de ciências da Universidade de Lisboa-centro de biologia Ambiental defendida em 2008 pela acadêmica Joana Isabel da Silva Carvalho que tem como título: Comportamento social em Chimpanzés (Pan Troglodytes versus): Manutenção de Estatuto Social e Hierarquia Social de Dominância. Em sua dissertação de mestrado, Carvalho, tinha como objetivo de sua pesquisa descrever e analisar o comportamento e organização de um grupo cativo de chimpanzés que residem no Jardim zoológico de Lisboa, desde 1993. Carvalho (2008), a partir do seu objetivo elenca sete hipóteses a serem testadas, são elas: 1) existem comportamentos que mostram uma organização hierárquica estável na colônia de Chimpanzés? 2) existem diferenças comportamentais entre os diferentes sexos? 3) existem diferenças comportamentais entre as várias idades? 4) existem diferenças comportamentais entre os sexos? 5) são exercidos 
diferentes papéis sociais nesta colônia de chimpanzés? 6) existem estratégias políticas entre os chimpanzés dessa colônia? 7) existem comportamentos estereotipados nos indivíduos da colônia?

A partir do material elencado acima, a autora da presente investigação, delimita o seu objeto de estudo. Segundo ela, os registros de zoo atestam que todos os chimpanzés da colônia pertencem a subespécie Pan Troglodytes verus. Em 2008, no ano de realizam desta pesquisa, a colônia era composta por composta por dois machos ( $n=1$ adulto e $n=1$ infantil) e várias fêmeas ( $\mathrm{n}=5$ adultas; $\mathrm{n}=1$ juvenil e $\mathrm{n}=3$ infantis) de idades variáveis. A tabela 1 apresenta algumas características dos chimpanzés. As categorias de idade foram adaptadas segundo Meder (1992): adultos (> 8 anos), subadultos (6-8 anos), juvenil (3-6 anos), infantil (1-3 anos) e cria (<1 ano). Segue a seguir a tabela de composição da colônia de Pan Troglodytes verus.

Tabela 2. Composição da colônia de Pan Troglodytes verus do jardim zoológico de Lisboa.

\begin{tabular}{|c|c|c|c|c|}
\hline Nome & Género & Idade & $\begin{array}{l}\text { Local e data } \\
\text { nascimento }\end{array}$ & $\begin{array}{c}\text { Progenitores } \\
\qquad(\delta /+)\end{array}$ \\
\hline DÁRI & Macho & $22^{*}$ & $\begin{array}{l}\text { Nascido em liberdade } \\
\qquad(1986)^{*}\end{array}$ & - \\
\hline KALI & Fêmea & $20^{*}$ & $\begin{array}{l}\text { Nascido em liberdade } \\
(1988)^{*}\end{array}$ & - \\
\hline JOCA & Fêmea & $18^{*}$ & $\begin{array}{l}\text { Nascido em liberdade } \\
(1990)^{\star}\end{array}$ & - \\
\hline GUGU & Fêmea & 13 & JZ (Setembro 1995) & Maria Pia/Buba** \\
\hline ANDREIA & Fêmea & 11 & JZ (Janeiro 1997) & -/Kali \\
\hline TATA & Fêmea & 11 & JZ (Março 1997) & -/Joca \\
\hline TUXA & Fêmea & 8 & JZ (Novembro 2000) & -/Joca \\
\hline GABI & Fêmea & 3 & JZ (Junho 2005) & -/Gugu \\
\hline KIKA & Fêmea & 2 & JZ (Junho 2006) & -/Kali \\
\hline JOY & Fêmea & 1 & JZ (Setembro 2006) & -/Joca \\
\hline TODY & Macho & 1 & $J Z$ (Abril 2007) & Dári/Tata \\
\hline- & Indefinido & - & JZ (Março 2008) & Dári/Andreia \\
\hline
\end{tabular}

Fonte: Carvalho (2008)

\section{As instalações}


Segundo Carvalho (2008), os grandes primatas residem, desde 2007, em área chamada de "Templo dos Primatas". Tal espaço encontra-se divido em três grandes subáreas que alojam de forma separada chimpanzés, gorilas com colobos e orangotangos com gibões. Os referidos primatas possuem acesso a dois cativeiros: os chamados cativeiros interiores, que possuem entrada restrita aos funcionários do zoológico, e os exteriores, no qual se tem um acesso mais liberado. A coleta dos dados realizados por Carvalho (2008), ocorreu apenas nos cativeiros exteriores dos chimpanzés. Segue abaixo uma foto de satélite das instalações.

Figura 5- Imagem do Templo dos Primatas. O círculo nos mostra a área do cativeiro externo dos chimpanzés.

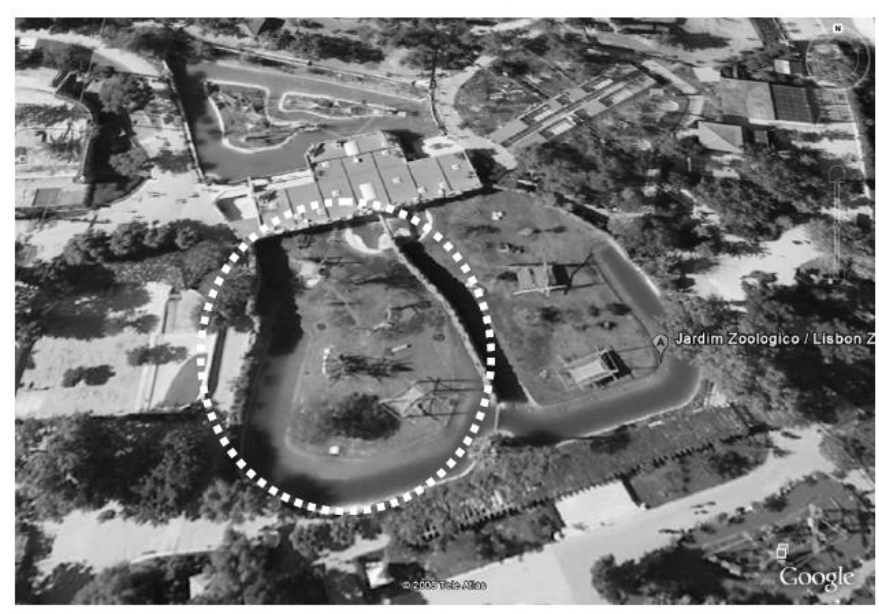

Fonte: Carvalho (2008)

Conforme atestado por Carvalho (2008), a área total do cativeiro exterior dos chimpanzés é de $1190 \mathrm{~m}^{2}$ e encontra-se isolada por três frentes de água, que permite o acesso ao pública a uma distância de $6 \mathrm{~m}^{2}$. Dentro de tal cativeiro podem ser encontradas plataformas de madeira, cordas, troncos, e caixas com os mais variados alimentos, A localização deste cativeiro permite que os chimpanzés tenham contato visual e auditivo com várias espécies de primatas alocadas no zoo. (CARVALHO,2008)

\section{Discussão dos resultados}

Segundo Carvalho (2008), houve uma notória variação comportamental entre os 
chimpanzés, e os time budgets ${ }^{9}$ demonstraram a forma como os animais corresponderam as condições sócio ecológicas e demográficas.

Tal colônia destinou grande parte do seu tempo a realização de comportamentos de manutenção ${ }^{10}$ e afiliativos ${ }^{11}$. As observações de carvalho (2008), nos mostra que no grupo dos comportamentos de manutenção, era possível observar um elevado número de comportamentos passivos. Esta variação foi observada a partir da correlação negativa entre comportamentos passiveis e os de alerta $^{12}$. As inúmeras observações (alerta-deslocação) também demonstraram que Joca é o responsável por realizar uma ronda e/ou patrulha do território, tal comportamento também foi observado em Dári. Os referidos comportamentos, segundo a autora deste estudo, nos permitem inferir que tanto Joca como Dário ocupam uma posição elevada de dominância. É importante também deixar registrado que nestas rodas o filhote de Dári estava muitas vezes acompanhando o pai. Nos estudos longitudinais realizados nesta pesquisa não foram registrados a participação de fêmeas em patrulhas. As observações realizadas por Carvalho (2008), sugerem um padrão de comportamento no que tange as patrulhas, porém, existem casos particulares que fogem ao habitual. Em 1986 Goodall apresenta o caso da fêmea Gigi que por ser estéril realizava rondas juntamente com os machos de seu grupo. As fêmeas, na pesquisa aqui referida, passaram boa parte do tempo desenvolvendo comportamentos de caráter de deslocação, e no caso da Tata e Gugu, os filhotes estavam sempre presentes. Segundo Goodall (1986), tais dispersões são características das fêmeas que vivem em ambiente natural, segundo a autora, elas desenvolvem este comportamento como tática de redução de competição por recursos e também como estratégia para evitar confrontos agonísticos ${ }^{13}$ para que possam, desta forma, garantir o sucesso

\footnotetext{
${ }^{9}$ É um registro ou diário da sequência e duração das atividades realizadas por um indivíduo durante um período especificado, normalmente o dia de 24 horas.

${ }^{10}$ Os comportamentos considerados de manutenção são: 1) Autocatagem (com ajuda dos dedos das mãos os indivíduos retiram pequenas partículas de sujeira que estão sobre seus corpos); 2) alerta (emissão de vocalização); 3) beber água; 4) construção de ninho; 5) deslocação (o indivíduo desloca-se pelo cativeiro); 6) descansar; 7) dormir; 8) forragear

${ }^{11}$ Os comportamentos considerados afiliativos são: 1) abraçar (pode ser mútuo e pode vir a ocorrer com um ou ambos os braços); 2) alocatagem (o indivíduo afasta o pelo do receptor com o polegar e o indicador e remove partículas da pele e do pelo); 3) andar junto (tandem/buddy walking), padrão comportamental que inclui dois indivíduos deslocando-se lado a lado e um deles com o braço sobre os ombros ou dorso do outro chimpanzé; 4) aproximar ( o ato de deslocar-se em Knuckle walking, próximo de um chimpanzé; 5)beijar; 6) convite a deslocação; 7) exibição na frente de visitantes; 8)inspeção facial e dentária; 9) jogos solitários ou sociais; 10) pedir alimentos.; 11) solicitar catagem; 12) pedir alimento aos visitantes

${ }^{12}$ Vocalização: pants- grunt. A comunicação entre primatas se dá por meio da emissão de sons e das posturas faciais ou corporais. Os chimpanzés utilizam a vocalização como forma de alterar o comportamento dos demais membros do grupo. É constatado um enorme repertório de sons com as mais diferenças gradações. O pant-grunt é iniciado por um indivíduo subordinado que o emite na direção de um indivíduo de posição social superior à sua, reconhecendo assim o seu estatuto social inferior perante o indivíduo dominante. (COLLINGE, 1993).

${ }^{13} \mathrm{Em}$, comportamento agonístico é qualquer comportamento social relacionado à luta. Portanto, é uma categoria mais ampla que , pois não envolve apenas o ato agressivo em si, mas também exibições, fugas, conciliação. São
} 
reprodutivo. Segundo Carvalho (2008), nesta colónia estudada os chimpanzés alimentavam-se majoritariamente pela manhã. Os adultos apresentaram um comportamento elevado de forrageio em comparação com os filhotes, pois os filhotes, enquanto os pais se alimentavam, se envolviam em jogos sociais. (GOODALL, 1986). Além do forrageio, segundo Carvalho (2008), os comportamentos sexuais ${ }^{14}$ estiveram mais presentes nos adultos. A Tuxa foi a fêmea que demonstrou uma maior duração de comportamentos classificados como sexuais.

As observações de Carvalho (2008), atestam que as fêmeas passaram boa parte do seu tempo desenvolvendo comportamentos classificados como afiliativos, tais comportamentos mostram-se predominantes na maioria das interações sociais desempenhada por tal grupo animal. "A afiliação, cooperação e tolerância social são benefícios mutualistas a longo prazo que vão estruturar a formação de grupos sociais, já a agressão e competição são estratégias sociais e ajustes individuais com benefícios efémeros e imediatos. (CARVALHO,2008, p. 46). Podemos dizer que a relação positiva que encontramos entre os comportamentos sociais (afiliativos) e os de caráter agressivo se devem à uma grande proximidade física que tais comportamentos exigem, tais contatos, como ocorrem de forma constante, podem vir a gerar episódios de agressão de uns para com os outros. Para a autora do presente estudo, este contato frequente, revelam que quanto maior o grau de parentesco dos indivíduos maior é o controle de comportamentos agressivos entre os pares. Outra descoberta instigante se refere ao fato da existência de uma relação entre o grau de parentesco com comportamentos parentais de andar sobre o dorso ou sobre o ventre, pois tais comportamentos, normalmente, são observados entre filhotes e chimpanzés adulto/adolescentes com um grau de parentesco.

Os cuidados parentais ao longo das observações, segundo Carvalho (2008), foram muito solicitados pelos filhotes. A correlação negativa obtida entre tais comportamentos e as alocatagens refletem, justamente, a importância dos papeis sociais desenvolvidos pelas fêmeas adultas, pois além de prestarem auxílio para seus filhotes também devem fortalecer seus laços sociais com o resto do grupo. Os jogos sociais ${ }^{15}$, em boa parte das vezes, foram desenvolvidos

\footnotetext{
tipo de comportamentos agonísticos: 1) ameaça; 2) bater; 3) exibição (display); 4) submissão (o indivíduo aproxima-se do outro e vocaliza pants-grunts pedindo desculpas; 5) fuga; 6) perseguição.

${ }^{14}$ Os comportamentos considerados sexuais são: 1) automasturbação; 2) cópula ;3) solicitar cópula

$15 \mathrm{O}$ jogo social tem uma diversidade de funções que estão de acordo com a idade, o sexo e a espécie (Paquette 1994) e com os benefícios obtidos a longo prazo (Bekoff e Byers 1981) ou a curto prazo no caso dos adultos (Pellis e Iwaniuk 2000; Palagi, Cordoni e Borgognini Tarli 2004).Palagi (2006) que o tipo de estrutura social reflecte nos adultos a maior incidência deste comportamento, verificando-se na estrutura igualitária dos bonobos uma maior frequência e na estrutura despótica dos chimpanzés uma frequência menor. Nesta colónia, os jogos sociais ocorreram maioritariamente entre os infantis Kika, Joy, Gabi e Tody, o que sugere que ocompanheiro preferencial de um infantil para brincar é quase sempre um outro infantil. Quando ojogo social se estendeu aos adultos, os infantis interagiram preferencialmente com a progenitora.Este facto realça a presença do grau de parentesco e da
} 
com a intenção de promover o cuidado para com os filhotes, sendo daí a correlação positiva obtida entre estes dois grupos comportamentais (CARVALHO,2008). Para a autora o andar no torço não esteve vinculado à nem um tipo de estratégia política nos casos observados, porém, segundo Casanova (1996, 2002), alguns episódios vivenciados pela Gugu podem evidenciar tal fato. "A Gabi deslocava-se no dorso da mãe ou em conjunto. A Tata quando se deparava com a ausência do infantil deslocava-se rapidamente ao seu encontro. Em nenhum contexto se verificou conflitos agonísticos entre tais fêmeas. (CARVALHO, 2008.p.48). Algumas fêmeas escolhem os filhotes de outras e passam a nutrir um grande interesse para com eles, bem como passam a desempenhar um cuidado maior para com tais filhotes. O fato é que tal escolha não é aleatória, mas sim seletiva (double-hold) a escolha do filhote se dá em razão do status social da mãe do filhote escolhido. Isto nos sugere que elas sabem que, aquele filhote, mais tarde herdara o status social que hoje pertence a mãe da referida cria, gerando, desta forma, uma garantia de segurança e tolerância nos recursos na posteridade. Tal comportamento político pode vir a ser aprovado ou rechaçado pelas fêmeas do grupo, gerando, desta forma, um conflito agonístico.

Nos estudos realizados por Carvalho (2008), os comportamentos de caráter submissos foram relativamente baixos, tais números podem vir a serem justificados pelo fato de alguns indivíduos interagirem em pequeno grupo o que, de certa forma, provoca um isolamento maior entre os indivíduos do grupo. A única ocorrência de conciliação foi verificada após os conflitos suscitados por Dári. Tais estratégias sugerem que, tais fêmeas, atestaram um comportamento inadequado de Dário e, a partir disso, atuaram a fim de acalmar o oponente. A estratégia da conciliação apresenta grandes vantagens, pois além de pôr fim ao conflito repara as relações sociais fragilidades pelo desentendimento, criando desta forma uma confiança mútua entre os indivíduos. Segundo De Wall (1996), as regularidades nas relações sociais favorecem os estatutos sociais, protegendo, desta forma, os membros dominantes e garantindo, assim, a segurança e o acesso a recursos por parte dos subordinados.

\section{Articulações conceituais entorno do caso empíricos}

A partir da análise do caso empírico elencando se faz necessário algumas articulações

intimidade neste tipo de interacção, quepode resultar da dependência ainda verificada nestes infantis. Daí a correlação positiva obtidaentre estes comportamentos e os parentais. Os jogos sociais ocorreram minoritariamente entre adultos e adulto-subadulta, verificando-se que os parceiros preferidos de jogo são os queparticipam nas alocatagens. Deste modo sugere-se que o jogo social não é exclusivo doschimpanzés mais novos, somente apresenta uma redução ao longo da vida de um chimpanzé .(Casanova 1996). 
conceituais entorno dos conceitos de empatia, cooperação e moralidade para que possamos argumentar em favor da hipótese de que os fundamentos da moralidade são naturais. Visto isso, encontramos alguns traços daquilo que denominamos como fenômeno moral em outras espécies de mamíferos sociais de vida complexa. Desta forma, traremos alguns indícios importantes observados no estudo etológico visitado por este trabalho.

Os comportamentos afiliativos observados por Carvalho (2008), mostram-se de extrema importância para a criação e a manutenção de vínculos afetivos entre os pares da referida colônia. Tais comportamentos, permitem, que os membros deste grupo desenvolvam a empatia entre si o que levará a uma cooperação mútua entre os indivíduos. Sendo assim, podemos sugerir uma interdependência entre o mecanismo empático e os mecanismos cooperativos nas comunidades de mamíferos sociais de vida complexa. Não é possível pensarmos a vida em comunidade de tais seres sem supormos o funcionamento combinado de tais mecanismos. $\mathrm{O}$ desenvolvimento da empatia entre os mamíferos sociais de vida complexa leva de forma automática a comportamentos cooperativos e comportamentos cooperativos levam necessariamente ao desenvolvimento empático, eis a primeira conclusão. O caso observado por Carvalho (2008), aonde o filhote Dári estava muitas vezes acompanhado pelo pai (ver página 17) atesta a nossa hipótese. O pai de Dári desenvolveu um comportamento pouco comum para machos da sua espécie, pois na maioria das vezes, o cuidado parental é realizado pela fêmea. Tal variação comportamental se deve ao fato de o pai de Dári ter desenvolvido comportamentos mais empáticos do que os demais machos, levando-o, desta forma, a um comportamento de carácter cooperativo.

Um outro caso que nos chama a atenção e sustenta a nossa hipótese é no caso aonde Tata e Gugu estavam sempre presentes com suas mães durante a deslocação para que pudessem estar seguros de possíveis ameaças (ver página 18). Este é outro caso que caso que atesta a nossa hipótese, pois, assim como no caso anterior, são os laços empáticos que levam a atos cooperativos. Desta forma, concordamos com a afirmação de Carvalho (2008, p.46): “ A afiliação, cooperação e tolerância social são benefícios mutualistas a longo prazo que vão estruturar a formação de grupos sociais". A observação que realizamos do caso empírico sugere que quanto maior o grau de parentesco dos indivíduos maior é o controle agressivo entre eles. Este fato observado sugere o controle agressivo se dá justamente pelos laços empáticos que envolvem tais seres. Tal observação sustentam a afirmação humeana a respeito de que quanto maior a proximidade entre os indivíduos maior também é o grau empático entre eles. (HUME, 2004). 
Tanto os jogos sociais (ver nota de rodapé na página 13) como a prestação de auxílio por partes das fêmeas (ver página 21) sugerem assim como os demais exemplos acima uma articulação necessária entre o mecanismo de empatia e os mecanismos de cooperação para a manutenção das comunidades de mamíferos sociais de vida complexa. A vida deste grupo animais torna-se impensável sem atuação em conjunto de tais mecanismos.

Partindo do pressuposto da necessidade dos fenômenos empáticos e cooperativos para a manutenção e evolução da vida social de tais comunidades, torna-se razoável pensar que tais mecanismos surgem como alicerces fundamentais para o surgimento daquilo que denominamos de comportamentos morais, ou mais especificamente, mostram-se essenciais para o desenvolvimento da nossa capacidade de censura e aprovação moral. A empatia e a cooperação, nos casos analisados, levam ao desenvolvimento de comportamentos que poderiam ser denominados de morais. O comportamento político desempenhado pelas fêmeas (ver página 21) sugerem algo muito próximo a julgamentos morais instigados por um sentimento de injustiça por parte de algumas fêmeas, que ao verem que seus filhotes poderiam estar sendo "usados" para fins estritamente políticos rechaçam as fêmeas responsáveis por tais atos, gerando, desta forma, um conflito agonístico. Relatos semelhantes a estes são comuns também em casos de comunidades observadas na natureza por Goodall (1986) e Casanova (2002). Aonde chimpanzés, desempenham papéis políticos muitas vezes muito próximos aos nossos governantes, assumindo a liderança, mediando conflitos e etc...

Por mais que o estudo de caso etológico trazidos neste artigo não nos tragam um número suficiente de evidências empíricas necessárias para uma conclusão definitiva, ela nos fornece uma gama de subsídios que sustenta tanto a presença de mecanismos empáticos como de cooperação em tais grupos, apontando, desta forma, a plausibilidade da existência de uma capacidade de censura e aprovação moral na espécie analisada. Partimos do pressuposto de que, por mais que talvez não tenhamos provas cabais que sustentem a existência do fenômeno moral em tais espécies nos trouxemos uma nova contribuição para área responsável pela investigação dos fundamentos da moralidade, isto é, a metaética. Ao trazermos uma nova maneira de compreender a moralidade, destacamos que o fenômeno moral possa, ou talvez até mesmo deva ser pesquisado pela via naturalista que de maneira não egóica nos coloca em simetria com as demais formas de vida presentes na terra.

\section{Considerações finais}


Neste artigo defendemos hipótese de que a moral naturalizada tem como fundamento o mecanismo empático e os mecanismos cooperativos. Ambos, atuam conjuntamente, são responsáveis pela manutenção das relações sociais entre os indivíduos, relação essa, que é garantidora do seu sucesso evolutivo.

Para defendermos a nossa hipótese buscarmos abordar, em um primeiro momento, a viabilidade de tal empreendimento de pesquisa elencando os pontos de contato entre a teoria moral humeneana com as ciências naturais. Ao passo que logramos êxito em tal demonstração pudemos assentar o caminho para o desenvolvimento desta pesquisa, bem como justiçar a importância da mesma inferindo os ganhos potenciais que a mesma traria para o entendimento da natureza humana e, em decorrência disso, para os fundamentos da moralidade.

Após a demonstração da viabilidade da pesquisa nos concentramos em salientar os princípios gerais da filosofia moral de Hume. Os estudos humeneanos atuaram como sustentáculos desta investigação na medida em que, Hume, apresentar um novo olhar a respeito dos fenômenos morais, ao demonstrar a não capacidade da razão em dar sustentação aos fundamentos morais, é exposto uma via para a construção de uma base para a moral: o empirismo. Hume, em seus escritos, ao tratar o fenômeno empático como basilar para o surgimento da moral nos abre uma via de pesquisa até então inexplorada, a via empíricoexperimental. Nossa pesquisa, adotando por base tal via, não poderia deixar de ressaltar os principais avanços alcançados por um dos seus idealizadores, eis a nossa tentativa de, assim como Hume, introduzir métodos experimentais nos assuntos pertinentes ao campo da filosofia moral.

Seguidamente, nos propusemos a tratar diretamente dos dois mecanismos que se apresentam como peças chaves deste artigo, a empatia e a cooperação. Desenvolvemos uma reflexão a respeito dos mecanismos necessários para que haja a evolução da cooperação e discutimos a noção moderna de empatia, bem como a de Hume. A referida discussão conceitual serviu como base teórica indispensável para que tenhamos conseguido lograr êxito na análise do nosso caso empírico.

Posteriormente, realizamos a análise do caso empírico a fim de que o mesmo servisse de aporte para a defesa de nossa hipótese. A análise do caso se mostrou satisfatória, pois logramos êxito ao identificar vários indícios da atuação mutua do mecanismo empático como dos mecanismos de cooperação. Os múltiplos casos de atuação dos referidos mecanismos sustentam a hipótese da sua significativa importância para a manutenção da vida em grupo de mamíferos sociais de vida complexa, sugerindo assim que como tais fenômenos são 
indispensáveis para o viver social de tais animais. Aquilo que chamamos de moralidade só pode vir a surgir a partir da mútua ocorrência destes dois mecanismos, pois sem a atuação de ambos não há vida em grupo e sem vida grupo não existe a possiblidade de ocorrência de fenômeno moral. Eis que concluímos que existem pelo menos dois fundamentos para o fenômeno moral segundo estudos de casos etológicos, a empatia e a cooperação.

\section{Referências Bibliográficas}

ALEXANDER, R. The Biology of Moral system. De Gruyter, New York, 1987.

AVELAR, T. MATOS,M. Seleção de Parentesco e altruísmo. Análise Psicológica, 1-2-3 (VII),p.57-62, 1989.

AXELROD, R. The evolution of Cooperation. Basic Books, New York, 1984.

BARD, K. (2007). Neonatal imitation in chimpanzees (Pan Troglodytes) tested with two paradigms. Animal Cognition, 10, 233-242.

BRITO, A. N. de. 2001. Hume e o empirismo na moral. Philósophos, Goiânia, v.6, n. 1 e 2, p.11-25.

CASANOVA, C., R. CEBALlOS, P.C. LEE. Innovate Social Behavior in Chimpanzees, 2008.

Introdução à Antropologia Biológica: Princípios Evolutivos, Genética e Primatologia.Lisboa: ISCSP,2006.

Pan troglodytes. American Journal of Primatology, 70: 54-61.

CARVALHO, J. Comportamento Social em Chimpanzés ( Pan troglodytes): Manutenção de Estatuto Social e Hierarquia Social de Dominância, Lisboa. 2008.68f. Dissertação (Mestrado em Biologia Humana e Ambiente)- Faculdade de ciências da Universidade de Lisboa- Centro de Biologia Ambiental.

COLLINGE, N. Introduction to Primate Behavior. Kendall/Hunt Publishing Company. Iowa, 1993.

CRAILSHEIM. et al. Social competence of adult chimpanzees (Pan troglodytes) with severe deprivation history: I. An individual approach.Developmental Psychology, [s.1.], v. 47, n. 1, p.77-90, 2011. American Psychological Association (APA).

DARWIN, C. The Origin of Species by Means Of Natural Selection, or the Preservation of Favored Races in the Struggle for Life. 6 ed.London: John Murray, 1872a.

The expression of the emotion in Man and Animals. New York. D Appleton Company, 1872b. 
The Descent of man, and selection in relation to sex. New Jersey. Princeton University. 1981.961p.

DARWALL,S.(1998).Empathy,sympathy, care.Philosophical Studies, 89,261-282.7

DE WAAL, F. Good natured: The origins of right and wrong in humans and other animals. Cambridge, MA: Harvard University Press, 1996. 1989. Food sharing and reciprocal obligations among chimpanzees. Journal of Human Evolution, 18: 433-459.

DUNBAR, R. I. M. The social brain hypothesis. Evolutionary Anthropology, 6, 178-190, 1998.

ESTRADA, A. Comportamiento animal: el caso de los primates. México: Fondo de Cultura Económica, 1991. 172 p.

FISHER,RA. The genetical Theory of Natural Selection. Clarendon Press, Oxford, 1930.

GOODALL, J. The Chimpanzees of Gombe. Patterns of Behavior. The Belknap Press of Havard University Press. Cambridge, Massachusets, and London, England,1986.

HAMILTON, W.D. The genetical evolution of social behaviour. I,II. J. Theor Biol.7,1$52,1964$.

HEPPER,P,G. Kin recognition: functions and mechanisms. A review. Biol.Rev,1986.

HUME, D. Investigações sobre o entendimento humano e sobre os princípios da moral. Traduzido por José Oscar de Almeida Marques. São Paulo, Unesp, 2004.

Tratado da natureza humana: uma tentativa de introduzir o método experimental de raciocínio nos assuntos morais. Traduzido por Débora Danowski. São Paulo, Unesp, 2009.

Do contrato original. In: Ensaios Morais, Políticos e Literários. Lisboa: Imprensa Nacional-Casa da moeda, 2002

HU, H.Y, et al.Evolutionofthehuman-specificmicroRnAmiR-941. NatureCommunications 3:1145|DoI:10.1038/ncomms2146, 2012.

LIEBERMAN, C.et al. Nature 433, 312, 2005.

MESQUITA, M. O papel dos mecanismos psicobiológicos de sociabilidade no comportamento moral, 2015,143f. Tese. (Tese em filosofia)- Escola de Humanidades, Universidade do Vale do Rio dos Sinos, São Leopoldo.

NOWAK,M. Five Rules for the Evolution of Cooperation. Science, vol 314, 2019.

KREBS,J.R. DAVIES,N.B. An introduction to behavioural ecology.2nd. Oxford: Ed. 
Blackwell Scientific Publication,1987.

REALE, G. História da Filosofia: do Humanismo a Kant. São Paulo, Paulus, 1990.

PLUTCHIK, R. (1987). Evolutionary bases of empathy. In: N. Eisenberg, \& J. Strayer (Eds.), Empathy and its development (pp. 38-46). New York: Cambridge University Press.

TUGENDHAT, E. Lições sobre ética. 1. ed. Petrópolis: Vozes, 1997

PRESTON, S. D. DE WALL, F. B. M. (2002). The communication of emotions and the possibility of empathy in animals. In: Altruistic love: Science, philosophy, and religion in dialogue, ed. S. Post, L. G. Underwood, J. P. Schloss \& W. B. Hurlburt. Oxford University Press. 